\title{
THE ANTIPLASMODIAL ACTIVITY OF CHALCONE DERIVATIVES THROUGH THE INHIBITION OF HEMOZOIN FORMATION ANDTHE INCREASED NUMBER OF STOMATOCYTES
}

\author{
Lilik Wijayanti'1), Bambang Purwanto'), Ambar Mudigdo²), Mustofa3), \\ Heri Suwito4), Paramasari Dirgahayu5), Muthmainah6) \\ 1)Doctoral Program in Medicine, Faculty of Medicine, Universitas Sebelas Maret \\ 2)Department of Anatomic Pathology, Faculty of Medicine,Universitas Sebelas Maret \\ 3)Department of Pharmacology and Therapy, Faculty of Medicine, \\ Universitas Gajah Mada \\ 4)Department of Chemistry, Faculty of Science and Technology, Universitas Airlangga \\ 5)Department of Parasitology, Faculty of Medicine, Universitas Sebelas Maret \\ 6) Department of Anatomy, Faculty of Medicine, Universitas Sebelas Maret
}

\begin{abstract}
Background: Malaria remains an important public health problem in the world, particularly due to resistance to Plasmodium. The presence of resistance encourages research to find new antimalarials. One of the compounds which has antiplasmodial activity is chalcone derivative compound (E) - 1 - (4 aminophenyl) - 3 - (2,3 - dimethoxyphenyl) prop - 2 - en - 1 - one. This study aimed to test if antiplasmodial compound worked by inhibiting Hemozoin formation and increasing the number of Stomatocytes.

Subjects and Method: This was an experimental laboratory study using a randomized controlled trial. The study was conducted from May 2016 until July 2017 in the laboratory of Parasitology and Clinical Pathology Faculty of Medicine, Universitas Gadjah Mada.A sample of Swiss mice wasrandomized into treatment group and control group.The independent variable was the administration of (E) - 1 - (4 - aminophenyl) - 3 - (2,3 - dimethoxyphenyl) prop - 2 - en - 1 - one. The dependent variable was the number of Hemozoin and Stomatocyte. Hemozoin level was measured by flow cytometry. The number of Stomatocytes was calculated from the peripheral blood picture stained with HE. The data were analyzed byt-test.

Results: The number of Hemozoin in the treatment group (mean=0.31) was less than in the control group (mean $=3.20)$ and it was statistically significant $(\mathrm{p}<$ o.001). The number of Stomatocytes in the treatment group (mean=38.83) was higher than in the control group (mean= 0.83 ) and it was statistically significant $(\mathrm{p}<0.001)$.

Conclusion: Substance (E) - 1 - (4 - aminophenyl) - 3 - (2,3 - dimethoxyphenyl) prop - 2 - en - 1 - one acts as an antimalarial by inhibiting Hemozoin formation and increasing the number of Stomatocytes.
\end{abstract}

Keywords: antimalarial, hemozoin, compound (E) - 1 - (4 - aminophenyl) - 3 (2,3 - dimethoxyphenyl) prop - 2 - en - 1 - one, stomatocytes

\section{Correspondence:}

Lilik Wijayanti. Doctoral Program in Medicine, Faculty of Medicine, Universitas Sebelas Maret, Jl.Ir.Sutami 36A, Surakarta 57126, Central Java, Indonesia. Email:lilikw8o@yahoo.com. Mobile: 081548719418.

Mid-International Conference on Public Health, Best Western Premier Hotel, Solo, Indonesia, 18-19 April 2018 | 251 https://doi.org/10.26911/mid.icph.2018.05.13 